\title{
AVALIAÇÃO DA PRODUTIVIDADE DE GRÃOS E DE BIOMASSA EM DOIS HÍBRIDOS DE MILHO SUBMETIDOS À DUAS CONDIÇÕES DE ADUBAÇÃO NO MUNICÍPIO DE SANTARÉM - PA
}

\author{
Antonia Mirian Nogueira de Moura Guerra ${ }^{1 *}$, Júlia Batista Azevedo Ferreira², Thaís Silva Vieira², Jaci \\ Roecker Franco ${ }^{2}$, Ana Cecília Moura Costa², Paula Raniele Freitas Tavares²
}

\begin{abstract}
RESUMO - Com o desenvolvimento da exploração avícola na cidade de Santarém/PA, o uso da cama de aviário como fertilizante é uma opção atrativa para a exploração de culturas como soja e milho, bem como hortaliças. O objetivo deste trabalho foi estudar a produtividade de grãos e de biomassa de dois híbridos de milho submetidos a duas condições de adubação no município de Santarém/PA. Foi avaliada a combinação entre dois fatores, cultivares e adubação. As cultivares híbridas de milho foram: Híbrido CD384Hx Coodetec ${ }^{\circledR}$ e Híbrido DKB350 VTPRO DEKALB ${ }^{\circledR}$. Na adubação com cama de aviário foram adotadas as doses de 0 e 2 t.ha ${ }^{-1}$. O delineamento experimental foi em blocos casualizado no esquema fatorial 2 x 2, com quatro repetições. A semeadura do

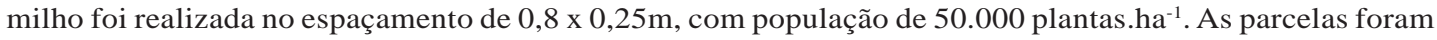
constituídas por oito linhas de 3,0m de comprimento, com uma área total de 14,4 $\mathrm{m}^{2}$ e parcela útil de $8,0 \mathrm{~m}^{2}$. Foram avaliadas: altura de planta e de inserção da primeira espiga; diâmetro do colmo e da espiga; comprimento de espiga; prolificidade; fileiras de grãos/espiga e grãos na fileira; grãos/espiga; peso de 100 grãos e produtividade. A cama de aviário proporcionou incrementos no número de fileiras e de grãos/fileiras e por sua vez, no tamanho das espigas, em comprimento e diâmetro, devido a um melhor desenvolvimento vegetativo (altura e diâmetro de planta). O fornecimento da cama de aviário proporcionou incrementos da ordem de 20,16\%, 33,34\% e 46,95\% no híbrido CD384Hx, e de 39,52\%, 42,45\% e 61,54\% no DKB350 VTPRO, para o número de grãos/ espiga, peso de 100 grãos e produtividade, respectivamente, quando comparados ao cultivo sem a adubação. O híbrido DKB350 VTPRO produziu maior número de grãos/espigas bem como, grãos mais pesados e maior produtividade do que o CD384Hx, quando fornecido a cama de aviário. Nas condições de Santarém/PA, ambos os híbridos foram produtivos, podendo recomendar o seu cultivo, porém com o fornecimento de cama de aviário o híbrido DKB350 VTPRO apresentou maior produtividade.
\end{abstract}

Palavras chave: CD384Hx, DKB350 VTPRO, grãos por espiga, Zea mays L.

\section{EVALUATION OF GRAIN AND BIOMASS PRODUCTIVITY IN TWO CORN HYBRIDS SUBMITTED TO TWO FODDER CONDITIONS IN THE MUNICIPALITY OF SANTARÉM - PA}

\begin{abstract}
With the development of the poultry farm in the city of Santarém/PA, the use of the aviary bed as fertilizer is an attractive option for the exploration of crops such as soybean and corn, as well as vegetables. The objective of this work was to study the grain and biomass productivity of two maize hybrids submitted to two fertilization conditions in the municipality of Santarém/PA. The combination between two factors, cultivars and fertilization was evaluated. The hybrid maize cultivars were: Hybrid CD384Hx Coodetec ${ }^{\circledR}$ and Hybrid DKB350 VTPRO DEKALB ${ }^{\circledR}$. The dose of 0 and 2 t.ha-1 was used in fertilization with aviary bed. The experimental design was randomized blocks in the $2 \times 2$ factorial scheme, with four replications. Corn sowing was performed
\end{abstract}

\footnotetext{
${ }^{1}$ Docente do curso de Agronomia da Universidade Federal do Oeste da Bahia, Centro Multidisciplinar Campus de Barra, Av. 23 de Agosto s/nº, Bairro Assunção, CEP: 47100-000, Barra - BA. E-mail: mirianagronoma@hotmail.com.*Autor para correspondência.

${ }^{2}$ Discente do curso de Agronomia da Universidade Federal do Oeste do Pará, Instituto de Biodiversidade e Florestas (Unidade Tapajó), Rua Vera Paz, s/nº, Bairro Salé, CEP:68035-110, Santarém - PA.
} 


\begin{abstract}
at a spacing of $0.8 \times 0.25 \mathrm{~m}$, with a population of 50,000 plants. ha ${ }^{-1}$. The plots were constituted by eight lines of $3.0 \mathrm{~m}$ in length, with a total area of $14.4 \mathrm{~m}^{2}$ and a useful plot of $8.0 \mathrm{~m}^{2}$. The following were evaluated: plant height and first ear insertion; stem and tang diameter; length of spike; prolificity; rows of grain/ear and grain in row; grain/ear; 100 grain weight and productivity. The aviary bed provided increases in the number of rows and grains/rows and, in turn, the size of the spikes, in length and diameter, due to a better vegetative development (height and plant diameter). The supply of the aviary bed provided increases of the order of $20.16 \%, 33.34 \%$ and $46.95 \%$ in the hybrid CD384Hx, and of $39.52 \%, 42.45 \%$ and $61.54 \%$ in the DKB350 VTPRO the number of grains/ear, weight of 100 grains and productivity, respectively, when compared to the crop without fertilization. The hybrid DKB350 VTPRO produced higher number of grains/ears as well as heavier grains and higher productivity than the CD384Hx when supplied to the aviary bed. In the conditions of Santarém/PA, both hybrids were productive and may recommend their cultivation, but with the supply of aviary bed, the hybrid DKB350 VTPRO presented higher productivity.
\end{abstract}

Keywords:CD384Hx, DKB350 VTPRO, grains per spike, Zea mays L.

\section{INTRODUÇÃO}

O milho (Zea mays L.) representa um dos principais cereais cultivados no Brasil. É cultivado em todo o território nacional em diferentes níveis de tecnologia, sendo a produção centralizada no Centro-Oeste, Sul e Sudeste. Embora responda por aproximadamente 3\% da produção nacional de milho, a região Norte vem despontando no cenário nacional, e o estado do Pará apresentou uma área de 259.100 ha, produção de 816.600 t e produtividade de $3.152 \mathrm{~kg} \mathrm{ha}^{-1}$ (Conab, 2017). Um dos fatores que tem contribuído para que Santarém esteja em evidência na produção de milho é a abertura desta fronteira agrícola à exploração da cultura da soja, e este grão é uma alternativa de rotação de culturas, além do mais, o manejo da cultura, a adoção de cultivares híbridas altamente produtivas tem proporcionado incrementos em produtividade.

A estimativa da produtividade média de grãos obtida com a cultura do milho no Brasil está em torno de 5.409 $\mathrm{kg} \mathrm{ha}^{-1}$ na safra 2016/2017 ao considerar conjuntamente a primeira e segunda safra (Conab, 2017), considerada baixa quando comparada a produtividade de 10.570 $\mathrm{kg} \mathrm{ha}^{-1}$ dos Estados Unidos (Usda, 2016). De fato, a baixa produtividade brasileira está relacionada à fertilidade do solo e condições climáticas (Chioderoli et al., 2012), de maneira que o melhoramento genético busca híbridos específicos com elevado potencial produtivo adaptado às diversas regiões brasileiras.

$\mathrm{O}$ alto potencial produtivo da cultura do milho safra após safra é devido ao manejo e ao incremento nos programas de melhoramento genético do milho, de forma que a cada ano, pesquisadores vem buscando genótipos em que altas produtividades são estabelecidas em densidades populacionais de 70.000 até 100.000 plantas ha-1 ${ }^{-1}$ e sob espaçamentos reduzidos, entre 45 a $60 \mathrm{~cm}$ (Fornasieri Filho, 2007).

As características fisiológicas permitem ao milho um alto potencial produtivo, já tendo sido obtida no Brasil produtividade superior a $16 \mathrm{t} \mathrm{ha}^{-1}$, em concursos de produtividade de milho conduzidos por órgãos de assistência técnica e extensão rural e por empresas produtoras de semente (Embrapa, 2010); onde notase também que a fertilidade do solo é um dos principais fatores responsáveis por essa baixa produtividade (Coelho \& França, 1995).

A adubação orgânica diferencia-se da química por ser de liberação lenta, tendo em contrapartida uma ação mais prolongada, além de favorecer a formação e estruturação da microflora normal do solo (Embrapa, 2007). As tabelas de adubação para fósforo e potássio são baseadas em parâmetros de análise de solo. Um redimensionamento da adubação para maiores produtividades requer a correção adequada da acidez do solo e o fornecimento balanceado de macro e micronutrientes.

Os resíduos orgânicos são muito utilizados para a adubação dos diferentes cultivos em todas as regiões do Brasil. A cama de aviário é uma alternativa muito utilizada e que se sobressai por apresentar maior concentração de nutrientes, quando comparado aos dejetos de gado ou de suínos (Comissão, 2004). Todavia, há uma demanda por maiores informações de viabilidade técnica e econômica para a disposição de alguns desses resíduos em solos agrícolas (Santos et al., 2011).

As camas de aves são uma excelente fonte de nutrientes e quando manejadas adequadamente, podem 
suprir, parcial ou totalmente, o fertilizante químico na produção de grãos. Além do benefício como fonte de nutrientes, seu uso adiciona matéria orgânica que melhora os atributos físicos do solo, aumenta a capacidade de retenção de água, reduz a erosão, melhora a aeração proporcionando um ambiente mais adequado para o desenvolvimento da flora microbiana do solo (Menezes et al., 2004).

Silva et al. (2011), ao avaliarem o efeito de doses de cama de aves e tempos de incubação, sobre o desenvolvimento inicial de plantas de milho, verificaram que a adição de 10,5 gramas de cama de frango por quilo de solo, incubadas por trinta dias, promoveram maior altura de plantas e biomassa seca de folhas e colmos de milho. Oliveira et al. (2008), por sua vez, ao avaliarem o efeito do emprego de doses de cama de frango, em cobertura, para fornecer 0, 50, 100 e 200 $\mathrm{kg} \mathrm{ha}^{-1} \mathrm{de} \mathrm{N}$, no desempenho de taro ou inhame (Colocasia esculenta), cultivado organicamente, sob sistema plantio direto, constataram incremento significativo na produtividade desta cultura, a qual atingiu produtividade máxima com a dose de aproximadamente $4,4 \mathrm{t} \mathrm{ha}^{-1} \mathrm{de}$ cama de frango (correspondente a $130 \mathrm{~kg} \mathrm{ha}^{-1} \mathrm{de} \mathrm{N}$ ).

Com o desenvolvimento da exploração avícola na cidade de Santarém - PA, o uso da cama de aviário como fertilizante é uma opção atrativa, principalmente, em virtude de sua produção em larga escala, além do crescente aumento da exploração de culturas como, soja e milho, bem como hortaliças, neste município. Apesar de já ser utilizada na adubação dessas culturas, ainda, existem poucos estudos sobre a influência da cama de frango na produtividade de híbridos de milho e a sua influência sobre a produtividade de genótipos altamente exigentes em fertilidade conduzidos nas condições amazônicas. Diante do exposto, o objetivo desta pesquisa foi estudar a produtividade dos híbridos de milho, CD384Hx Coodetec ${ }^{\circledR}$ e DKB350 VTPRO DEKALB ${ }^{\circledR}$, adubados com cama e sem cama de aviário, em experimento conduzido no município de Santarém - PA.

\section{MATERIALE MÉTODOS}

O trabalho foi conduzido em lavoura comercial localizada na comunidade de Boa Esperança, zona rural do município de município de Santarém - PA $\left(02^{\circ} 24^{\prime}\right.$ 52" S; 54 42' 36" W; $152 \mathrm{~m}$ de altitude) na mesorregião do Baixo Amazonas. O cli-ma da região segundo a classificação de Köppen, é do tipo Ami, tropical com uma estação anual seca de dois a três meses e precipitação anual média de $2.000 \mathrm{~mm}$, com alta pluviosidade de março a maio, e baixa pluviosidade de agosto a novembro; temperatura média anual de $25^{\circ} \mathrm{C},\left(18,4\right.$ a $\left.32,6^{\circ} \mathrm{C}\right)$; umidade relativa do ar de $86 \%$ (76-93\%) e uma insolação média anual de 2.150 horas e nebulosidade média anual oscilando de 5,6 e 0,6 décimos (Silva \& Nechet, 2006).

O solo da área é do tipo Latossolo Vermelho distrófico álico, textura argilosa (Embrapa, 2006). A análise do solo da área experimental $(0-20 \mathrm{~cm})$ apresentou as características: $\mathrm{pH}$ em $\mathrm{H}_{2} \mathrm{O}=6,2 ; \mathrm{P}=8,9 \mathrm{mg} \mathrm{dm}^{-3}$ (Mehlich 1); $\mathrm{K}=94$ $\mathrm{mg} \mathrm{dm}{ }^{-3} ; \mathrm{Ca}^{2+}=4,6 \mathrm{cmol}_{\mathrm{c}} \mathrm{dm}^{-3} ; \mathrm{Mg}^{2+}=1,3 \mathrm{cmol}_{\mathrm{c}} \mathrm{dm}^{-3}$; $\mathrm{H}+\mathrm{Al}=1,9 \mathrm{cmol}_{\mathrm{c}} \mathrm{dm}^{-3}, \mathrm{~S}=6,1 \mathrm{cmol}_{\mathrm{c}} \mathrm{dm}^{-3}, \mathrm{~V}=76 \% \mathrm{e}$ $\mathrm{M} . \mathrm{O}=28,7 \mathrm{~g} \mathrm{~kg}^{-1}$.

Foi avaliada a combinação entre dois fatores, cultivares e adubação com cama de aviário. As cultivares híbridas de milho foram: Híbrido CD384Hx Coodetec ${ }^{\circledR}$ (híbrido triplo, precoce indicado para safra e safrinha nas regiões Sul e Centro-Oeste, produção de grãos e silagem, com alto potencial produtivo, resistência ao acamamento, qualidade de grão, proteção contra lagartas e doenças do Complexo de mancha branca, Cercospora zeae-maydis, Puccinia polysora e Helminthosporium turcicum) (Coodetec, 2012) e Híbrido DKB350 VTPRO DEKALB ${ }^{\circledR}$ (híbrido que contém a Tecnologia YieldGard® que promove o controle da broca-do-colmo e a supressão da lagarta-do-cartucho e da lagarta-da-espiga, é altamente tolerante às principais doenças foliares, principalmente a Cercospora, tem um sistema radicular agressivo que permite superar os estresses hídricos, proporcionando ótima produtividade nos plantios de época normal e tardio, e excelente desempenho durante a safrinha) (DEKALB, 2014). Na adubação com cama de frango foram adotadas as doses de $0 \mathrm{e} 2 \mathrm{tha}^{-1}$. O delineamento experimental foi em blocos casualizados no esquema fatorial $2 \times 2$, com quatro repetições.

No preparo da área, realizou-se uma gradagem niveladora para incorporação dos resíduos da cultura da soja anteriormente semeada e na parcela com adubação orgânica, para incorporação da cama de aviário. Não foi realizada adubação de semeadura, pois utilizouse o residual da adubação adotada anteriormente no cultivo de soja, que foi de $200 \mathrm{~kg} \mathrm{ha}^{-1}$ do formulado 00-14-18. Nas parcelas que receberam adubação orgânica, foi usada a dose de $2 \mathrm{t} \mathrm{ha}^{-1}$ de cama de aviário. Não foi realizada adubação de cobertura. As sementes foram tratadas com fludiofonil + metaloxyl-M (37,5 + 112,5 
g do i.a. respectivamente) por $100 \mathrm{~kg}$. Para o controle de plantas daninhas em pós-emergência utilizou-se atrazina e tembotriona $\left(1000+105,0 \mathrm{~g} \mathrm{ha}^{-1}\right.$ do i.a. respectivamente) na forma de mistura no estádio $\mathrm{V}_{6}$ da cultura. Adicionou-se a calda de aplicação o adjuvante éster metilado de óleo de soja (720 $\mathrm{g} \mathrm{ha}^{-1}$ do i.a.).

A semeadura do milho foi realizada com plantadeira, sendo o espaçamento adotado de $0,8 \times 0,25 \mathrm{~m}$, com população de 50.000 plantas ha $^{-1}$. As parcelas foram constituídas por oito linhas de 3,0 m de comprimento, com uma área total de $14,4 \mathrm{~m}^{2}$, a bordadura constituiuse de uma fileira em cada lado da parcela, sendo que a parcela útil foi constituída por uma área de 3,2 x 2,5 m e área útil de $8,0 \mathrm{~m}^{2}$.

Foram realizadas as seguintes avaliações: a) altura de planta e altura de inserção da primeira espiga: onde mediu-se a altura de planta e da inserção de espiga em dez plantas ao acaso por parcela no florescimento pleno da cultura; b) diâmetro do colmo: com auxílio de um paquímetro digital mediu-se o diâmetro do colmo em dez plantas por parcela na altura de $25 \mathrm{~cm}$ do solo; c) comprimento de espiga: com uma régua milimetrada mediu-se o comprimento de dez espigas ao acaso por parcela; d) diâmetro de espiga: mensurou-se o diâmetro na porção mediana de dez espigas colhidas na área útil; e) prolificidade: referiu-se à relação entre o número de espigas pelo número de plantas existentes nas parcelas; f) fileiras de grãos por espiga e grãos na fileira: foi obtido pela contagem das fileiras e grãos nas fileiras em dez espigas colhidas por parcela; g) grãos por espiga: para esta avaliação, multiplicou-se o número de fileiras por espiga e grãos na fileira; h) peso de 100 grãos: foi realizada com base na pesagem de quatro subamostras de cem grãos por parcela com ajuste para 13\% de umidade; i) produtividade de grãos: após a colheita da área útil das parcelas as espigas foram trilhadas e após a pesagem, converteram-se os valores para 13\% de umidade (base úmida).

Para a análise estatística dos resultados obtidos, utilizou-se o programa estatístico SAEG (Ribeiro Júnior, 2001), sendo os tratamentos comparados entre si pelo teste de Tukey a $5 \%$ de probabilidade.

\section{RESULTADOS E DISCUSSÃO}

Não houve efeito significativo da interação Cultivares $\mathrm{X}$ Adubação, sendo observado efeito isolados dos fatores (Tabela 1).
A altura de planta, diâmetro de espiga, número de fileiras e prolificidade apresentaram ausência de significância $(\mathrm{P}>0,05)$ para os híbridos avaliados (Tabela 1). Entretanto, houve diferença estatística entre os híbridos para as demais variáveis, e o híbrido DKB350 VTPRO apresentou maior altura de inserção da espiga (13,83\%), diâmetro do colmo (12,84\%) e comprimento da espiga $(14,42 \%)$ em relação CD384Hx (Tabela 1). Carvalho et al. (2014) observaram efeitos significativos de genótipos ao ambiente de cultivo no estado do TO sobre a produção de grãos e massa verde de milho, justificando a necessidade da adaptabilidade e estabilidade de materiais a diferentes localidades. Rampim et al. (2013) também observaram que o híbrido DKB350 VTPRO apresentou maior altura de inserção da primeira espiga, comprimento de espiga em relação a outros híbridos. Assim, o híbrido DKB350 VTPRO pode ser considerado uma boa alternativa para o produtor que deseja comercializar milho em espiga, pois o consumidor tem preferência por aquelas de maior comprimento, além de que para o produtor tem-se uma relação direta com o ganho em produtividade.

Todas as variáveis foram afetadas significativamente pela adubação com cama de aviário, exceto a altura de planta (Tabela 1). Desse modo, houve incrementos de $17,33 \%$ para altura de inserção da espiga, de 20,41\% para o diâmetro do colmo, 25,5\% para o diâmetro da espiga, 26,24\% no comprimento da espiga, 9\% no número de fileiras e 36\% na prolificidade em relação a ausência de adubação com cama de aviário (Tabela 1). Os incrementos no tamanho das espigas, em comprimento e diâmetro, são devidos aos aumentos observados no número de fileiras e de grãos/fileiras, e tais aumentos pode-se atribuir a um melhor desenvolvimento vegetativo (altura e diâmetro de planta) favorecendo a manutenção das taxas fotossintéticas e consequente acúmulo de biomassa, e estes sendo promovidos pela adubação com a cama de aviário. Souza et al. (2016) observaram comportamento linear crescente para o diâmetro do colmo e número de folhas, em função do aumento das doses de cama de frango até $12 \mathrm{t} \mathrm{ha}^{-1}$. Silva et al. (2011), ao avaliarem o efeito de doses de cama de aves e tempos de incubação, sobre o desenvolvimento inicial de plantas de milho, verificaram que a adição de $10,5 \mathrm{~g}$ de cama de frango por quilo de solo, incubadas por trinta dias, promoveram maior altura de plantas e biomassa seca de folhas e colmos de milho. 
Tabela 1 - Altura de planta, de inserção da espiga, diâmetro do colmo e da espiga, número de fileiras e prolificidade de híbridos de milho CD384Hx e DKB350 VTPRO conduzidos sob adubação com cama de aviário, em Santarém - PA

\begin{tabular}{|c|c|c|c|c|c|c|c|}
\hline & $\begin{array}{l}\text { Altura de } \\
\text { planta }^{\text {ns }}\end{array}$ & $\begin{array}{c}\text { Altura de } \\
\text { inserção da } \\
\text { espiga** }\end{array}$ & $\begin{array}{l}\text { Diâmetro do } \\
\text { colmo** }\end{array}$ & $\begin{array}{l}\text { Diâmetro da } \\
\text { espiga }^{\text {ns }}\end{array}$ & $\begin{array}{l}\text { Comprimento } \\
\text { da espiga** }\end{array}$ & $\begin{array}{l}\text { Número de } \\
\text { fileiras }^{\text {ns }}\end{array}$ & Prolificidade $^{\text {ns }}$ \\
\hline & \multicolumn{4}{|c|}{$\longrightarrow \mathrm{m}$} & \multirow[t]{2}{*}{$\mathrm{cm}$} & & \\
\hline & & & & Cultivar & & & \\
\hline CD384Hx & $1,37 \mathrm{a}$ & $0,62 b$ & $53,15 b$ & 56,63a & $18,87 b$ & $17,97 a$ & $1,37 a$ \\
\hline DKB350 VTPRO & $1,59 a$ & $0,74 a$ & $60,98 a$ & $60,68 a$ & $22,05 a$ & $18,02 \mathrm{a}$ & $1,50 \mathrm{a}$ \\
\hline
\end{tabular}

Cama de aviário

\begin{tabular}{lccccccc} 
& $\begin{array}{c}\text { Altura de } \\
\text { planta }^{\text {ns }}\end{array}$ & $\begin{array}{c}\text { Altura de } \\
\text { inserção da } \\
\text { espiga** }\end{array}$ & $\begin{array}{c}\text { Diâmetro do } \\
\text { colmo** }^{* *}\end{array}$ & $\begin{array}{c}\text { Diâmetro da } \\
\text { espiga }^{\text {ns }}\end{array}$ & $\begin{array}{c}\text { Comprimento } \\
\text { da espiga** }\end{array}$ & $\begin{array}{c}\text { Número de } \\
\text { fileiras }^{\text {ns }}\end{array}$ & Prolificidade $^{\text {ns }}$ \\
Sem & $1,46 \mathrm{a}$ & $0,62 \mathrm{~b}$ & $50,58 \mathrm{~b}$ & $50,08 \mathrm{~b}$ & $17,37 \mathrm{~b}$ & $17,15 \mathrm{~b}$ & $1,12 \mathrm{~b}$ \\
$2 \mathrm{t} \mathrm{ha}^{-1}$ & $1,51 \mathrm{a}$ & $0,75 \mathrm{a}$ & $63,55 \mathrm{a}$ & $67,23 \mathrm{a}$ & $23,55 \mathrm{a}$ & $18,85 \mathrm{a}$ & $1,75 \mathrm{a}$ \\
$\mathrm{CV}(\%)$ & 16,99 & 4,37 & 9,03 & 8,42 & 11,98 & 2,32 & 23,90 \\
DMS & 0,28 & 3,39 & 5,83 & 5,58 & 2,77 & 0,47 & 0,38 \\
\hline
\end{tabular}

Médias na linha seguidas pela mesma letra não diferem entre si pelo teste de Tukey a 5\% de probabilidade. CV: coeficiente de variação. DMS: diferença mínima significativa. ${ }^{\text {ns }},{ }^{* *}$ ou *: não significativo, significativo a $1 \%$ ou $5 \%$ de probabilidade pelo teste $F$, respectivamente.

Menezes et al. (2004) afirmaram que a cama de frango pode atuar como condicionador do solo e promover melhoria em suas propriedades físicas e, consequentemente, facilitar a emergência de plântulas. É muito provável que esses resultados sejam um indicativo que a quantidade aplicada estava fornecendo os nutrientes necessários para que as plantas pudessem expressar o seu potencial de produção, não ocorrendo crescimento vegetativo excessivo em detrimento da produção, e sim, assegurando que este foi o responsável pela manutenção da produção.

Conforme dados da literatura, diversos são os benefícios do emprego de adubos orgânicos na melhoria da qualidade do solo e, consequentemente, no desenvolvimento e produtividade das culturas. De acordo com Siqueira \& Franco (1988) o acréscimo de resíduos orgânicos ao solo estimula a população microbiana e, com isso, a disponibilidade de nutrientes aumenta, resultando em melhor desenvolvimento de plantas.

Houve efeito significativo da interação Cultivares $\mathrm{X}$ Adubação sobre o número de grãos/espiga, peso de 100 grãos e produtividade (Tabela 2). Foram observadas diferenças significativas para os valores médios de número de grãos/espiga, peso de 100 grãos e produtividade entre os tratamentos, demonstrando a responsividade dos híbridos a adubação com cama de aviário. O fornecimento da cama de aviário permitiu incrementos da ordem de 20,16\% e 33,34\% para no híbrido CD384HX, e de 39,52\% e 42,45\% para o DKB350 VTPRO, para o número de grãos/espiga e peso de 100 grãos, respectivamente, quando comparados ao cultivo sem a adubação (Tabela 2). Nesse sentido, pode-se constatar que o híbrido DKB350 VTPRO tanto produziu maior número de grãos/espigas bem como grãos mais pesados do que o CD384Hx quando fornecido a cama de aviário, em contrapartida, na ausência de quaisquer tipos de adubação de plantio, o híbrido CD384Hx produziu apenas espigas com maior quantitativo de grãos (Tabela 2). Tollenaar (1992) afirma que mudança da arquitetura foliar na cultura do milho permitiu aos híbridos modernos manter maiores taxas fotossintéticas de folhas, em alta densidade, em relação aos híbridos clássicos, além de promover um aumento no uso eficiente da radiação solar durante o período de enchimento de grãos, que futuramente contribuirá para a produção de mais grãos por planta e maiores rendimentos de grãos por área.

Nota-se que ambos os híbridos aumentaram a produtividade na dose de $2 \mathrm{t} \mathrm{ha}^{-1}$ da cama de aviário quando comparados com o cultivo sem este adubo, porém o híbrido DKB350 VTPRO apresentou um aumento de 16,9\% em relação ao CD384Hx na condição de cultivo adubado (Tabela 2). 
Tabela 2 - Número de grãos por espiga, peso de 100 grãos e produtividade de híbridos de milho CD384Hx e DKB350 VTPRO conduzidos sob adubação com cama de aviário, em Santarém - PA

\begin{tabular}{|c|c|c|c|c|c|c|}
\hline \multirow[b]{2}{*}{ Cultivar } & \multicolumn{2}{|c|}{$\begin{array}{c}\text { Número de grãos/espiga** } \\
\text { Cama de aviário }\end{array}$} & \multicolumn{2}{|c|}{$\begin{array}{c}\text { Peso de } 100 \text { grãos }(\mathrm{g})^{*} \\
\text { Cama de aviário }\end{array}$} & \multicolumn{2}{|c|}{$\begin{array}{c}\text { Produtividade }\left(\mathrm{t} \mathrm{ha}^{-1}\right)^{* *} \\
\text { Cama de aviário }\end{array}$} \\
\hline & Sem & $2 \mathrm{t} \mathrm{ha}^{-1}$ & Sem & $2 \mathrm{t} \mathrm{ha}^{-1}$ & Sem & $2 \mathrm{t} \mathrm{ha}^{-1}$ \\
\hline CD384Hx & $481,72 \mathrm{Ab}$ & $603,37 \mathrm{Ba}$ & $20,27 \mathrm{Ab}$ & $30,41 \mathrm{Ba}$ & $5,14 \mathrm{Ab}$ & $9,69 \mathrm{Ba}$ \\
\hline DKB350 VTPRO & $418,47 \mathrm{Bb}$ & $691,95 \mathrm{Aa}$ & $18,96 \mathrm{Ab}$ & $32,95 \mathrm{Aa}$ & $4,46 \mathrm{Ab}$ & $11,66 \mathrm{Aa}$ \\
\hline DMS & \multicolumn{2}{|c|}{48,17} & \multicolumn{2}{|c|}{2,42} & \multicolumn{2}{|c|}{0,58} \\
\hline CV (\%) & \multicolumn{2}{|c|}{5,49} & \multicolumn{2}{|c|}{5,90} & \multicolumn{2}{|c|}{4,75} \\
\hline
\end{tabular}

Médias na linha seguidas pela mesma letra minúscula e na coluna seguidas de mesma letra maiúscula não diferem entre si pelo teste de Tukey a 5\% de probabilidade. CV: coeficiente de variação. DMS: diferença mínima significativa. ${ }^{\text {ns }}$, ** ou *: não significativo, significativo a $1 \%$ ou $5 \%$ de probabilidade pelo teste $F$, respectivamente.

Felini \& Bono (2011) observaram aumentos em produtividade em milho e soja com o uso de até $8 \mathrm{t}$ ha ${ }^{-1}$ de cama de aviário e que doses superiores não eram eficientes em solos de Cerrado e que da adubação praticada ficava um grande residual não aproveitado pela cultura, servindo como fonte de nutriente para o cultivo de safrinha, assegurando incrementos nos índices produtivos. Para produtividade de grãos de milho Reina et al. (2010) constataram aumento na produtividade com crescentes doses de esterco bovino quando comparada com a testemunha. Já em trabalho realizado por Pohlmann et al. (2009) concluiu-se que a adição de material orgânico propiciou rendimentos de milho verde semelhantes aos com adição de adubação química. Por outro lado, resultados semelhantes foram obtidos por Silva et al. (2008) onde observaram que a adubação orgânica + química obteve maiores rendimentos de produtividade do que o uso de material orgânico. De forma análoga, Zure et al. (2011) constataram que a produção do milho híbrido BM3061 alcança maiores valores quando utilizada a adubação química + orgânica, levando a incrementos de 9,7\% em relação a adubação orgânica.

Acredita-se que os incrementos nos componentes de produção e na produtividade alcançados com a adubação a partir da cama de aviário podem ser devido aos teores de nutrientes presentes no material orgânico. Pohlmann et al. (2009) avaliando incrementos na produtividade de milho adubados com cama de aviário, atribuíram os ganhos aos elevados teores de cálcio, fósforo e potássio presentes no material orgânico. Ribeiro et al. (1999) asseveram que o incremento no teor de potássio trocável com o uso dos compostos orgânicos é decorrente da disponibilização imediata da totalidade do elemento contido no composto logo no primeiro ano, enquanto que para o fósforo, a taxa de disponibilização no primeiro ano fica em torno de $60 \%$ do teor total contido no composto. Neste sentido, deve-se considerar que há uma reserva de aproximadamente $40 \%$ de fósforo orgânico que será liberado em anos posteriores, bem como de outros nutrientes que poderão beneficiar outros cultivos. Vale ressaltar que este trabalho foi conduzido em solo com residual de adubação mineral da cultura da soja, que inclusive contribuiu com a fixação de $\mathrm{N}$, com isso, mesmo sendo utilizadas doses de adubação orgânica baixas (2 t ha${ }^{1}$ ), os incrementos em produtividade devem-se tanto ao efeito conjunto da adubação e do residual, bem como ao desempenho do híbrido nessas condições. Assegurando que, se dispusermos de condições mínimas de adubação orgânica com cama de aviário, teremos sucesso na exploração de híbridos de milho em Santarém - PA, com destaque e produtividade para o híbrido DKB350 VTPRO.

\section{CONCLUSÕES}

A cama de aviário proporcionou incrementos no número de fileiras e de grãos/fileiras e por sua vez, no tamanho das espigas, em comprimento e diâmetro, devido a um melhor desenvolvimento vegetativo (altura e diâmetro de planta) que favoreceu a manutenção das taxas fotossintéticas e consequente acúmulo de biomassa.

O fornecimento da cama de aviário proporcionou incrementos da ordem de 20,16\%, 33,34\% e 46,95\% no híbrido CD384HX, e de 39,52\%, 42,45\% e 61,54\% no DKB350 VTPRO, para o número de grãos/espiga, peso de 100 grãos e produtividade, respectivamente, quando comparados ao cultivo sem a adubação.

O híbrido DKB350 VTPRO produziu maior número de grãos/espigas bem como, grãos mais pesados e maior produtividade do que o CD384Hx, quando fornecido a cama de aviário. 
No município de Santarém - PA, ambos os híbridos foram produtivos, podendo recomendar o seu cultivo, porém com o fornecimento de cama de aviário o híbrido DKB350 VTPRO apresentou maior produtividade.

\section{AGRADECIMENTOS}

Ao Sr. Hélio Franco pelo apoio logístico e operacional e doação da área para condução do experimento.

\section{LITERATURACITADA}

CARVALHO, E.V.; AFFÉRRI, F.S.; PELÚZIO, J.M. et al. Adaptabilidade na produção de massa verde e grãos de genótipos de milho no Tocantins.

Revista Ciência Agronômica, v.45, n.4, p.856-862, 2014.

CHIODEROLI, C.A.; MELLO, L.M.M.; GRIGOLLI, P.J. et al. Atributos físicos do solo e produtividade de soja em sistema de consórcio milho e braquiária. Revista Brasileira de Engenharia Agrícola e Ambiental, v.16, n.1, p.37-43, 2012.

COELHO, A.M.; FRANÇA, G.E. Seja o doutor do seu milho: nutrição e adubação. São Paulo: Encarte; Piracicaba: Potafós, 1995. p.1-9.

COMISSÃO DE FERTILIDADE DO SOLO - RS/ SC, 2004. Manual de adubação e de calagem para os estados do Rio Grande do Sul e de Santa Catarina. 10.ed. Porto Alegre, SBCS/NRS, 2004. 400p.

CONAB - Companhia Nacional de Abastecimento. Acompanhamento da safra Brasileira: grãos, nono levantamento junho 2017. Companhia Nacional de Abastecimento, Brasília: Conab, 2017. Disponível em: <http:// www.conab.gov.br/OlalaCMS/uploads/arquivos/ 17_06_08_09_02_48_boletim_graos_junho_2017.pdf $>$. Acesso em 01 de julho de 2017.

COODETEC. Guia de produtos 2012. 2017. Disponível em: <http://www.coodetec.com.br/php/ detalhes_cultivar.php?id=17>

DEKALB. Catálogo de híbridos de milho safrinha região Norte 2014/2015. 2017. Disponível em: <http://www.dekalb.com.br/ milho.aspx>. Acesso em 02 de junho de 2017.
EMPRESA BRASILEIRA DE PESQUISA

AGROPECUÁRIA - EMBRAPA. Cultivo do milho. Versão Eletrônica. 6. ed.: Embrapa Milho e

Sorgo, 2010. Disponível em: <http:// www.cnpms.embrapa.br/>. Acesso em: 03 jun. 2017.

EMBRAPA, Centro de Pesquisa Agropecuária do Oeste (Dourados, MS). Milho: informações.

Revista Brasileira de Agroecologia, v.2, n.1, 2007.

EMBRAPA. Centro Nacional de Pesquisa de Solos (Rio de Janeiro, RJ). Sistema brasileiro de classificação de solos. Ed. SANTOS et al. 2.ed. Rio de Janeiro: Embrapa Solos, 2006. 306p.

FELINI, F.Z.; BONO, J.A.M. Produtividade de soja e milho, em sistema de plantio com uso de cama de frango na região de Sidrolândia-MS. Ensaios e Ciência: Ciências Agrárias, Biológicas e da Saúde, v.15, n.5, p.9-18, 2011.

FORNASIERI FILHO, D. Manual da cultura do milho. Jaboticabal: Funep, 2007. 273p.

MENEZES, J.F.S.; ALVARENGA, R.C.; SILVA, G.P. et al. Cama de frango na agricultura: perspectivas e viabilidade técnica e econômica. Boletim técnico, n.3, 28p. 2004.

OLIVEIRA, F.L.; GUERRA, J.G.M.; ALMEIDA, D.L. et al. Desempenho de taro em função de doses de cama de aviário, sob sistema orgânico de produção. Horticultura Brasileira, v.26, p.149-153, 2008.

POHLMANN, R.A.C.; PAULINO, H.B.; PORTUGAL, A.F. et al. Alterações químicas do solo e rendimento de milho verde após aplicação de compostagem de carcaça de aves. In: Simpósio Internacional sobre Gerenciamento de Resíduos de Animais: Uso dos Resíduos da Produção Animal como Fertilizante, 1.

Anais...Florianópolis-SC, 2009.

RAMPIM, L.; ECCO, M.; ROSSET, J.S. et al. Desempenho de híbridos simples de milho segunda safra em semeadura direta. Cultivando o Saber, v.6, n.4, p.141-155, 2013.

REINA, E.; AFFÉRRI, F.S.; CARVALHO, E.V. et al. Efeito de doses de esterco bovino na linha de semeadura na produtividade de milho. Revista Verde de Agroecologia, v.5, n.5 (Número Especial), p.158-164, 2010. 
RIBEIRO A.C.; GUIMARÃES, P.T.G.; ALVAREZ, V.H. Comissão de fertilidade do solo do estado de Minas Gerais. Recomendações para o uso de corretivos e fertilizantes em Minas Gerais $-\mathbf{5}^{\mathbf{a}}$ aproximação. Viçosa, MG, 1999. 359p.

\section{RIBEIRO JÚNIOR, I.R. Análises estatísticas} no SAEG. Viçosa: UFV, 2001. 301p.

SANTOS, D.H; SILVA, M.A; TIRITAN C.S et al. Qualidade tecnológica da cana-de-açúcar sob adubação com torta de filtro enriquecida com fosfato solúvel. Ciência e Agrotecnologia, v.34, n.4, p.443-449, 2011.

SILVA, A.R.; NECHET, D. Características climáticas de alguns municípios produtores de soja do estado do Pará. In: CONGRESSO BRASILEIRO DE METEOROLOGIA, 14. Anais...Florianóplois-SC, 2006. Disponível em: http://www.cbmet.com/ edicoes.php?page

Num_Recordset_busca=4\&totalRows_Recordset_busca= 1006\&cgid=14. Acesso em: 10 de setembro de 2016.

SILVA, T.R.; MENEZES J.F.S.; SIMON, G.A. et al. Cultivo do milho e disponibilidade de $\mathrm{P}$ sob adubação com cama de frango. Revista Brasileira de Engenharia Agrícola e Ambiental, v.15, n.9, p.903-910, 2011.
SILVA, R.G., GALVÃO, J.C.C.; MIRANDA, G.V. et al. Produtividade de variedades de milho nos sistemas de cultivo orgânico e convencional. Revista Caatinga, v.21, n.2, p.78-85, 2008.

SIQUEIRA, J.O.; FRANCO, A.A. Biotecnologia do solo: fundamentos e perspectivas. Brasília: FAEP/ABEAS/MEC/ESAL. 1988. 236p.

SOUZA, F.M.; LIMA, E.C.S.; SÁ, F.V.S. et al. Doses de esterco de galinha e água disponível sob o desenvolvimento inicial do milho. Revista Verde, v.11, n.5, p.64-69, 2016.

TOLLENAAR, M. Is low plant density a stress in maize? Maydica, v.37, n.2, p.305-311, 1992.

USDA - States Department of Agriculture, by the National Agricultural Statistics Service (NASS), Agricultural Statistics Board, Crop production, 2016. Disponível em: <https:// www.nass.usda.gov/Publications/Ag_Statistics/ 2016/Chapter01.pdf>.Acesso em 01 de julho de 2017.

ZURE, G.E.O.; OLIVEIRA, V.M.; GOTARDO, M. et al. Produtividade de milho verde híbrido BM3061 sob diferentes tipos de adubação no plantio. Revista Verde, v.6, n.2, p. 184-188, 2011.

Recebido para publicação em 05/7/2017 e aprovado em 08/11/2017. 